\title{
Parametric study of Friction Stir Spot Welding (FSSW) for polymer materials case of High Density Polyethylene sheets: experimental and numerical study
}

\author{
Djilali Benyerou, El Bahri Ould Chikh, Habib Khellafi, Hadj Miloud Meddah \\ University of Mascara, LSTE Laboratory, 29000, Mascara, Algeria. \\ djilali.benyerou@univ-mascara.dv, bttps://orcid.org/0000-0003-1457-4403 \\ b.ouldchikh@univ-mascara.dz,https://orcid.org/0000-0002-7360-7677 \\ khellafi29@univ-mascara.d₹,hm.meddah@univ-mascara.dz.
}

\author{
Ali Benhamena \\ University of Mascara, LPQ3M Laboratory, 29000, Mascara, Algeria \\ ali.benhamena@univ-mascara.dz. \\ Kaddour Hachelaf, Abdellah Lounis \\ University of Mascara, LSTE Laboratory, 29000, Mascara, Algeria \\ kaddour.bachellaf@univ-mascara.d\%,lounis.abdallah@univ-mascara.dz.
}

\begin{abstract}
Friction stir spot welding (FSSW) is a very important part of conventional friction stir welding (FSW) which can be a replacement for riveted assemblies and resistance spot welding. This technique provides high quality joints compared to conventional welding processes. The FSSW is a new technology adopted to join various types of metals such as titanium, aluminum, magnesium. It is also used for welding polymer materials which are difficult to weld by the conventional welding process. In various industrial applications, high density polyethylene (HDPE) becomes the most used material. The parameters and mechanical properties of the welds are the major problems in the welding processes. In this paper, we have presented a contribution in finite element modeling of the FSSW process using finite element method (FEM). The objective of this paper is to study the HDPE plates resistance of stir spot welding joints (FSSW) using tensile test in the experimental part. First, we show the experimental tests results of HDPE plates assembled by FSSW. Three-dimensional numerical modeling by the finite element method makes it possible to determine the best representation of the weld joint for a good prediction of its behavior. Comparison of the results shows that there is a good agreement between the numerical modeling predictions and the experimental results.
\end{abstract}

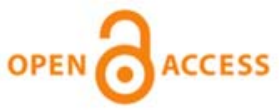

Citation: Benyarou, D., Ould Chikh, B., Khellafi, H., Meddah, H.M, Benhamena, A., Hachelaf, K., Lounis, A., Parametric study of Friction Stir Spot Welding (FSSW) for polymer materials case of High Density Polyethylene sheets: experimental and numerical study, Frattura ed Integrità Strutturale, 55 (2021) 145-158.

Received: 26.08 .2020

Accepted: 17.11 .2020

Published: 01.01.2021

Copyright: (C) 2021 This is an open access article under the terms of the CC-BY 4.0, which permits unrestricted use, distribution, and reproduction in any medium, provided the original author and source are credited. 
KEYWORDS. Polymers; Tensile tests; High-density polyethylene; FSSW; Numerical analysis; FEM.

\section{INTRODUCTION}

$\mathrm{P}$ olymer is a word of Greek origin, and it means poly (many) and mere (repetition unit). By the origin of the word, it can be inferred that polymers are structures formed by the repetition of many mere. The mere are connected by covalent bonds and the raw material that gives rise to the polymer is the monomer, which is the basic unit of repetition of polymers. The polymer can have very different characteristics, according to the type of monomer that forms it, the average number of monomers per polymeric chain and the type of covalent bond that is present. The polymer pipes offer several advantages: they have good resistance to wear and corrosion, low density, low cost, easy of installation, they have durability and reasonable mechanical resistance, production of complex shape [1,2]. These authors showed that the fracture behavior of high density poly-ethylene (HDPE) pipe is related to the loading condition, the shape and the position of crack in the wall of pipe. In other words, it is known, that during the process of forming solid materials, the plastic instability phenomena often control the appearance and performance of the finished product according to Moulai Ali et al. [3], Khellafi Habib [4], and Abdel Nour Zaim [5,6]. These authors examined the effect of stress triaxiality on the mechanical behavior response of polyvinylchloride (PVC), polybutylene terephthalate (PBT) and the Thermoplastic Copolyetherester (TPC) under large plastic strain. They have concluded that the damage evolution of PVC and PBT in service has influenced by the level of stress triaxiality. In addition, polymer pipes have another major advantage is that they can be assembled by fusion techniques which efficient and easy to implement techniques in industry field. Mostly, electrofusion welding and butt fusion welding are common methods for joining polyethylene pipes used for water and gas distribution in national and worldwide levels. Pathak and Pradhan [7] performed several experimental studies related to electrofusion and butt fusion welding of HDPE pipe in order to study the effect of some parameters such as: starting welding voltage, specific fusion time, and cooling time for electrofusion welding and for the butt fusion welding the heating plate temperature, drag pressure has been analyzed and its effects on the tensile strength of HDPE pipe. They concluded that the welding parameters of any welding process must be optimized. For this study, the optimized parameters for electro fusion welding of this HDPE pipes are welding voltage, specific fusion time, cooling time and optimized parameters for Butt welding are heating plate temperature, drag pressure, welding pressure. On the other hand, it is known that the conventional welding techniques (fusion welding) are more prone to the formation of defects in the material during the solidification process after melting the material, which leads to a decrease in the mechanical properties of welded joints. In addition, the procedure for conducting fusion welds requires both greater training for the operator and the use of appropriate clothing to ensure his safety. The need for protective gas during the process, affects the environment. Also, the use of the filler metal and the high energy levels required to perform fusion welds, increase the costs of the welding process. In this context, Bouchouicha et al. [8] analyzed the evolution of the energy at the crack tip taking into account the different conditions such as the mechanical aspects, stress conditions, geometry of the specimen and the effects of closing. The use of solid state welding (Friction Stir Welding: FSW) is an alternative to make joints in different types of materials: ferrous, non-ferrous, polymers, composites and different materials. FSW was developed in 1991 at the Welding Institute in England. The FSW technique, offers advantages in quality, as it avoids the melting of the material, which means a decrease in the tendency to form defects and better mechanical properties compared with conventional welding techniques [9]. The low heat input reduces distortions in the part especially in the weld region. The procedure for performing welds using the FSW technique is simple, does not require any filler metal and does not present any risks to the operator health compared to the fusion welding. In FSW process, several parameters are adjusted and must be checks to ensure the quality of the joints. According to Thomas and Nicholas [10] and Mishra and Ma [11], friction welding is part of a new generation of welding processes, which was recently developed with the ability to weld high-strength aluminum alloys, which are difficult to be welded by fusion welding process. Lee et al. [12] presented an experimental analysis in order to study the weldability of hot rolled AZ31B-H24 magnesium alloy by FSW. They found that the welding parameters such as tool rotation speed and linear welding speed has a great effect on the tensile strength of welded joints, an insufficient heat input, which was generated in the case of higher linear speed and lower rotation speed leading to an inner void or lack of bonding in the stir zone. In the industry field of Mazda [13], the engineers have introduced a new welding technology in the production of the RX-8 sports car. Use of the technology enabled Mazda to reduce electricity consumption by $99 \%$. Sundaram and Murugan [14] investigated experimentally the effect of friction stir 
welding parameters on the tensile strength of dissimilar welding joints of aluminium alloys welded by FSW. They indicated that the increase in tool rotational speed and welding speed leads to the increase in the tensile strength of the welded joints. In the same context, the effect of tool rotation speed on the microstructure and mechanical properties of butt welded dissimilar pure copper/brass alloy plates by friction stir welding have been carried out by Barlas and Uzun [15]. They have concluded that the grain size and the onion ring formation in the weld nugget zone and the mechanical properties of the joints were affected by tool rotation speed, these authors showed that the tensile strength of the joints was lower than that of the copper and brass base metals. A further examination of this subject can be found in [15-19]. Welding techniques for plastics are nowadays consolidated processes in several industrial areas [20, 21]. Strand et al. [22] carried out experimental work to investigate the relationships between several parameters of FSW process and its effect on the microstructural and flexural properties of a polymer welded joints. They showed that the pin diameter, feedrate, shoe temperature, and pressure time has a significant impact on mechanical properties of welded joint. Arici and Selale [23] investigate the effect of tool tilt angle on friction stir welding (FSW) of polyethylene (PE). They showed that the welding parameters had significant effects on tensile properties and fracture locations of the welds. The tensile strength decreased with increasing tool tilt angle. Similar study was carried out by Kiss and Czigany [24] to investigate the effect of rotation and translation speed on the joint strength of welded polypropylene sheets by FSW process. Aydin [25] investigate the weldability of UHMW-polyethylene via friction stir welding method. This author concluded that the preheating process increases the tensile strength of welded joint. Several authors [26-28] have presented a very interesting and comprehensive review regarding the effect and optimization of friction stir welding process parameters on the tensile strength of polymeric materials welded by FSW.

In 2001, a new derivative of friction stir welding (FSW) appeared, it is called the friction stir spot welding (FSSW). It was developed in the automotive industry to replace resistance spot welding for aluminum sheets [29]. Gerlich et al. [30] studied the feasibility of using the FSSW process using dissimilar materials, in the case of aluminum and Magnesium. These results reveal that the level of fracture loads is related to the energy input during FSW spot welding. Also, they showed a partial pull-out of the stir zone occurred in high energy input FSW spot welds with fracture initiating from unbonded regions located on either side of the welded joint. Arici and Mert [31] noticed the influence of tool penetration depth and dwell time on joint strength of lap joints of polypropylene welded by FSSW. It was concluded that the increases of dwell time improve the tensile shear and change the failure mode of welded joints. In the same subject, Bilici and his co-authors [32-35], presented interesting experimental results on friction stir spot welding of thermoplastics. They found that the tool geometry, tool rotational speed, tool plunge depth and dwell time were determined to be important in the joint formation and its strength. The (FSW) and (FSSW) welding provide significant advantages over traditional welding. They make it possible to weld materials which are difficult or impossible to weld with other welding techniques [13, 36]. FSSW have been employed for a wider range of metals including titanium, magnesium, copper and even high strength steels, also it has been successfully applied to thermoplastic sheets since 2003 [22]. This type of materials are employed for replacing metals in a wide range of industrial fields as, aerospace, automotive industry, navy, armament... because of their advantages, such as reduced manufacturing cost, weight saving, high thermal insulation, the investment of less equipment, excellent mechanical properties, respecting the environment, weaker requirement of energy and aptitude for automation [28]. In FSSW, frictional heat is generated by the interaction of the tool pin with the material that becomes pasty and extrudes vertically. The tool shoulder then exerts an upsetting action on the stirred material to form the weld nut. The operation of friction stir spot welding FSSW consists in providing heat to basic material by friction between the tool and the plates to be welded and by plastic dissipation. The FSSW process of thermoplastics consists of four phases; plunging, stirring, solidifying and retracting as shown in Fig. 1. In FSSW process, firstly the two plates to be welded are fixed to restrict the deformations caused by the welding process. The FSSW process has four stages: plunging, stirring, solidifying and retracting according to Fig. 1 [32-34]. Tool rotates and plunged into the attached work pieces with force to a certain depth. In the stirring phase the tool doesn't plunge. This operation generates a frictional heat. Then, heated and softened material adjacent to the tool deforms plastically, and a solid state bond is made between the surfaces of the upper and lower sheets.

The tool consists of two parts, the shoulder and the pin. The pin generates friction heat, deforms the material around it and stirs the heated material [30]. In FSSW, several parameters such as the geometry of the tool, the rotation speed, the plunge depth, the dwell time and material type affect directly the friction stir spot welding nugget formation and the weld strength [32]. In this work, we focus on the weldability of a polymer (HDPE) by the friction stir spot welding technique (FSSW). These polymers are used in water and gas transporting pipes (CHIALI group) [37-40]. This study is a contribution to a parametric analysis in order to optimize the welding parameters which are necessary to understand their effects in order to obtain a good weld quality. and to understand the behavior of the assembly by proposing a numerical 
model which predicts the global behavior of the weld using the finite element method to optimize the FSSW welding parameters of HDPE sheets. We recall also, that the present study is an extension of previous studies $[37,38]$.

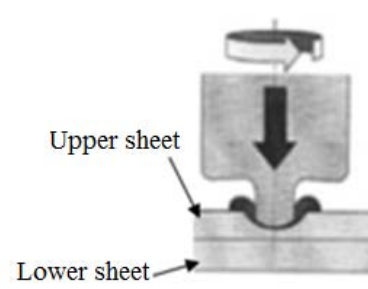

a) Plunging

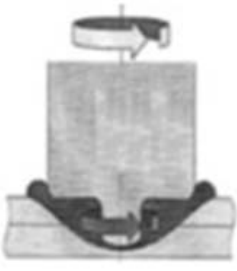

b) Stirring

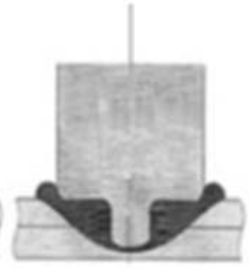

c) Solidification

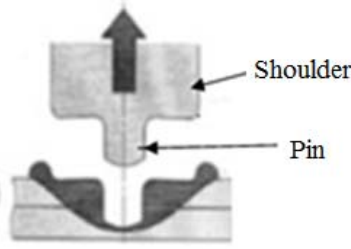

d) Retracting

Figure 1: Friction stir spot welding process [32].

\section{EXPERIMENTAL PROCEDURE}

\section{Materials and specimens}

$\mathrm{W}$

e have used a standard polyethylene with high density HDPE, of molar mass that is about $500 \mathrm{~kg} / \mathrm{mol}$. The temperatures of vitreous transition and fusion are respectively of $-125^{\circ} \mathrm{C}$ and $135^{\circ} \mathrm{C}$, and the density is equal to $0.97 \mathrm{~g} / \mathrm{cm}^{3}$. It is about a semi-crystalline thermoplastic comprising a crystalline phase and an amorphous phase. This polymer is used generally in the manufacture of pipes reserved for the supply and distribution of water in accordance with NA7700-2 standards manufactured by the CHIALI group [39]. Physical and mechanical characteristics are given in Tab. 1.

\begin{tabular}{lll}
\hline Characteristics & Units & PE100 \\
\hline Density & $\mathrm{kg} / \mathrm{m}^{3}$ & $956-961$ \\
Melt Flow Index MFI $\left(190{ }^{\circ} \mathrm{C} ; 5 \mathrm{~kg}\right)$ & $\mathrm{g} / 10 \mathrm{mn}$ & $0.2-0.5$ \\
Resistance at the yield point & $\mathrm{MPa}$ & $\geq 19$ \\
Elongation at break & $\%$ & $>600$ \\
Elasticity modulus & $\mathrm{MPa}$ & 1000 \\
Fragility temperature & ${ }^{\circ} \mathrm{C}$ & $<-100$ \\
Linear expansion & $\mathrm{K}^{-1}$ & 24.104 \\
Electrical resistance & $\Omega / \mathrm{cm}$ & $\geq 1012$ \\
\hline
\end{tabular}

Table 1: Physical and mechanical characteristics of $\operatorname{HDPE}[38,39]$

The Friction Stir Spot Welding (FSSW) welding process is new and has received great attention from the automotive, aeronautical and other industries. This welding technology involves a process similar to that of FSW linear friction-mixing welding [37, 38], except that the tool, instead of moving along a butt joint, only penetrates an overlapping joint (lap joint) formed by the plates (Fig. 2). This process can be explained, basically, by three distinct stages: penetration, mixing and indentation. In this way, the process starts with the rotary tool slowly penetrating the weld point until the head touches the upper plate (penetration). Then, the mixing stage begins, which allows the plates to join, and finally the recoil of tool. The recoil is done quickly, just after the tool reaches the final depth of penetration or after a dwell time (dwell), in which the tool only rotates at the maximum depth determined. During the process, heating due to friction softens the material, the rotation of the pin is responsible for the material flow in the radial and axial directions, and the pressure applied by the tool head allows the formation of solid weld around the pin. Finally, after withdrawing the tool, a characteristic exit hole is left.

A high-density polyethylene (HDPE) sheets with a thickness of $4 \mathrm{~mm}$, a width of $60 \mathrm{~mm}$, and a length of $150 \mathrm{~mm}$ were used to study the FSSW welding under shear conditions loading. Fig. 2 shows the specimen dimensions and the tool 
position during the FSSW welding process. The specimens were welded on a semi-automatic milling machine (Fig. 3) using a steel tool GS 235 (steel E36) whose geometry is presented in Fig. 4 [38]. This tool is suitable for friction welding FSSW of HDPE plates. It is able to perform the three main welding functions:

Heat the parts by friction and by plastic deformation

Mix the materials to form the joint

Contain the flow of material under the shoulder and around the pin.

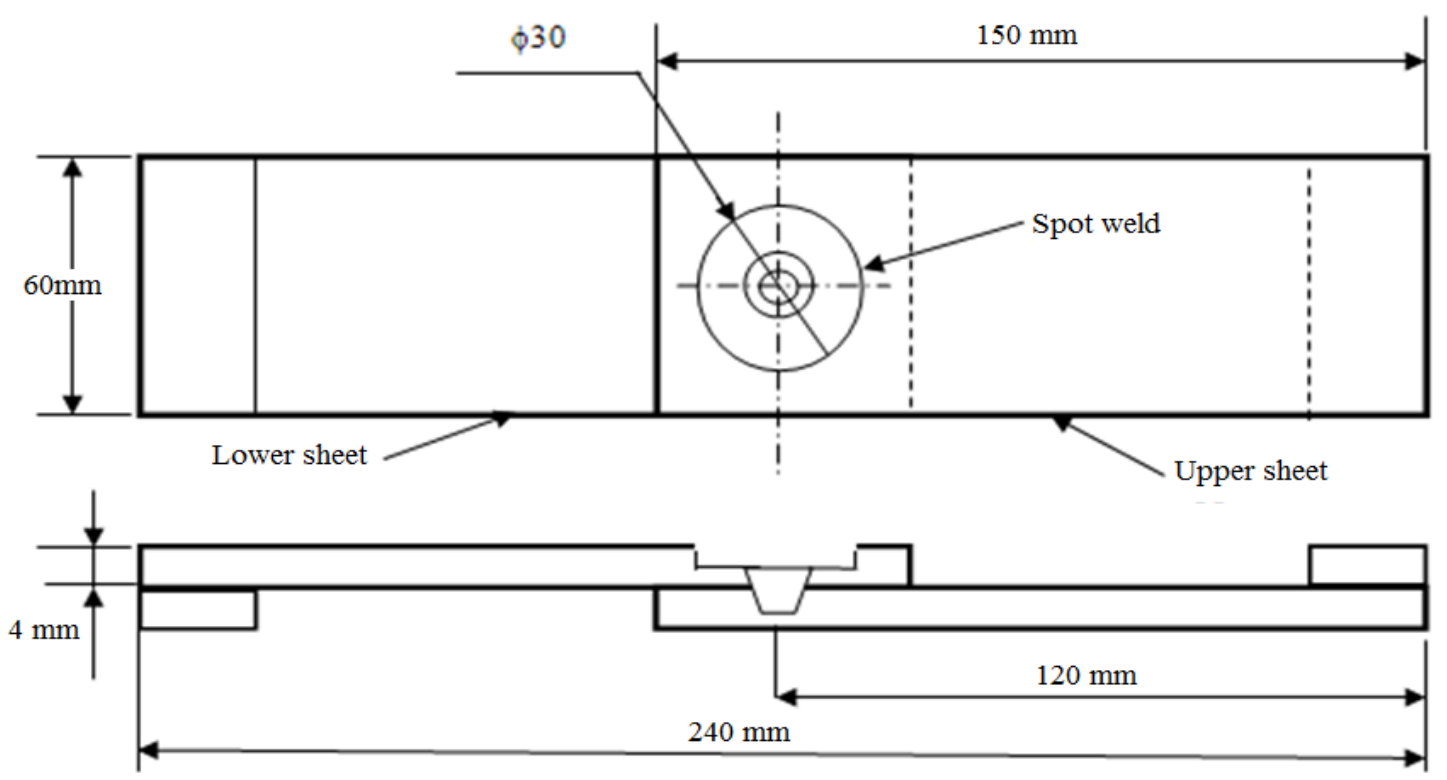

Figure 2: Specimen geometry and tool position for the FSSW process

The shoulder is used to provide heat by friction and to knead the material under the effect of the rotational speed of tool. The milling machine has the necessary characteristics for welding by FSSW. The HDPE plates are fixed to the machine table by flat metal shims which are held in place by fixing the plates one on the other in order to ensure a uniform distribution of the pressure on the specimen test [38].

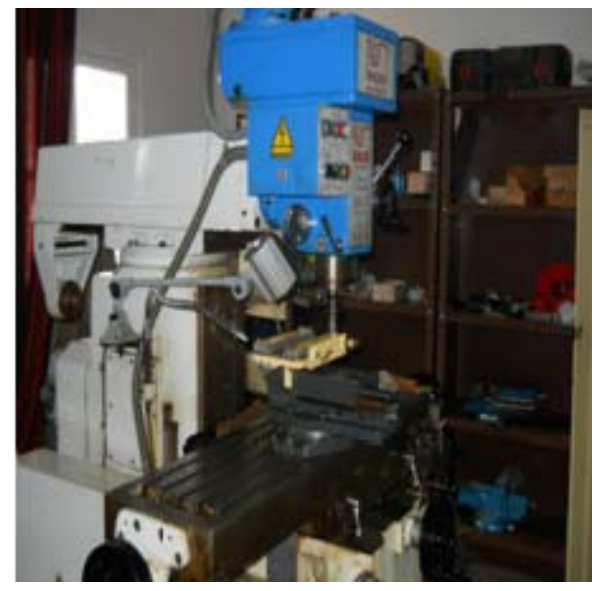

Figure 3: milling machine

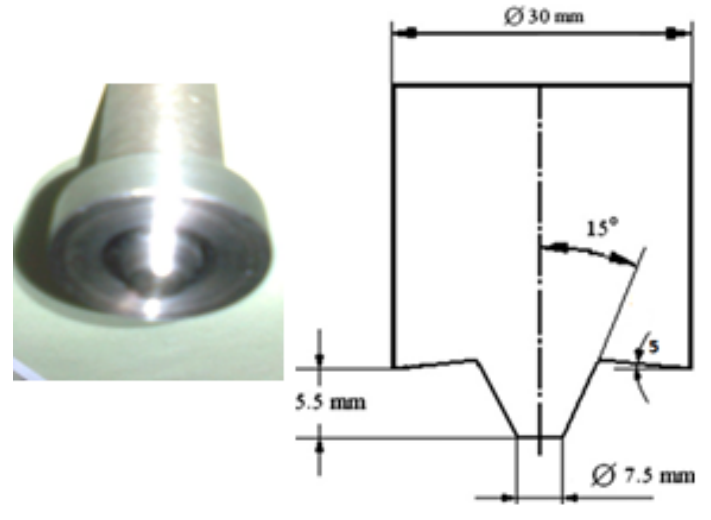

Figure 4: FSW welding tool

The experimental campaign was performed by means of a milling machine in order to weld by FFSW an HDPE lap shear joint. Several tests were carried out by varying tool rotational speed and dwell time. A typical HDPE lap shear joint specimen used for testing is shown in Fig. 2. To investigate the influence of tool rotational speed on the failure load and strength of bonded joints, three different values overlap length values were chosen: 750, 875 and $1100 \mathrm{rpm}$ and by varying of dwell time. All the welding conditions for each performed test are tabulated in Tab. 2. All in all, 36 different tension test series are performed. 


\begin{tabular}{|c|c|c|c|}
\hline Specimens ID & $\begin{array}{l}\text { Tool rotation } \\
\text { speed (rpm) }\end{array}$ & Dwell time (S) & $\begin{array}{l}\text { Mean value of maximum } \\
\text { shearing force }(\mathrm{N})\end{array}$ \\
\hline PC _1 & 750 & 60 & \\
\hline PC _2 & 750 & 60 & 1366 \\
\hline $\mathrm{PC}_{-} 3$ & 750 & 60 & \\
\hline $\mathrm{PC}_{-} 4$ & 875 & 60 & \\
\hline $\mathrm{PC} \_5$ & 875 & 60 & 1832 \\
\hline PC _6 & 875 & 60 & \\
\hline $\mathrm{PC}_{-} 7$ & 1100 & 60 & \\
\hline $\mathrm{PC} \_8$ & 1100 & 60 & 686 \\
\hline PC_9 & 1100 & 60 & \\
\hline PC _10 & 750 & 90 & \\
\hline PC _11 & 750 & 90 & 1450 \\
\hline$P C \_12$ & 750 & 90 & \\
\hline PC _13 & 875 & 90 & \\
\hline PC _14 & 875 & 90 & 1111 \\
\hline PC _15 & 875 & 90 & \\
\hline PC _16 & 1100 & 90 & \\
\hline PC _17 & 1100 & 90 & 1815 \\
\hline PC_18 & 1100 & 90 & \\
\hline PC _19 & 750 & 120 & \\
\hline PC _20 & 750 & 120 & 1511 \\
\hline$P C \_21$ & 750 & 120 & \\
\hline PC _22 & 875 & 120 & \\
\hline PC _23 & 875 & 120 & 1723 \\
\hline$P C \_24$ & 875 & 120 & \\
\hline PC _25 & 1100 & 120 & \\
\hline PC _26 & 1100 & 120 & 2155 \\
\hline PC _27 & 1100 & 120 & \\
\hline PC _28 & 750 & 150 & \\
\hline PC _29 & 750 & 150 & 2032 \\
\hline$P C \_30$ & 750 & 150 & \\
\hline PC _31 & 875 & 150 & \\
\hline PC _32 & 875 & 150 & 1151 \\
\hline$P C \_33$ & 875 & 150 & \\
\hline PC _34 & 1100 & 150 & \\
\hline $\mathrm{PC} \_35$ & 1100 & 150 & 733 \\
\hline PC _36 & 1100 & 150 & \\
\hline
\end{tabular}

Table 2: Welding parameters ranges.

All the welding operations were done at the room temperature. At the beginning of each welding operation, the pin and the shoulder of the tool were cooled to the room temperature.

The joint shape is presented in Fig. 5 which shows the appearance of the test specimen after the friction stir spot welding. The tool shape is transferred onto the joint on the upper sheet and the metal that is pushed out by the tool forms a ring of excess metal around the weld. 


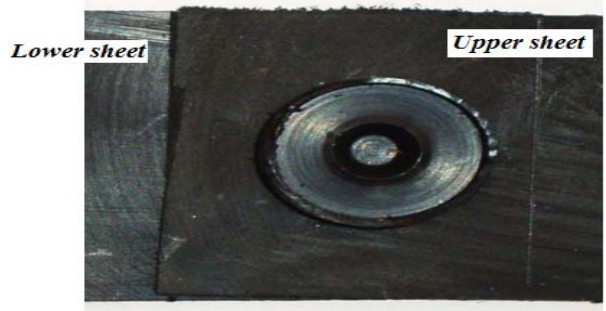

Figure 5: friction stir spot weld joint.

We can resume the different welded joint shapes obtained by different welded parameters (tool rotation speed and dwell time) in Tab. 3.

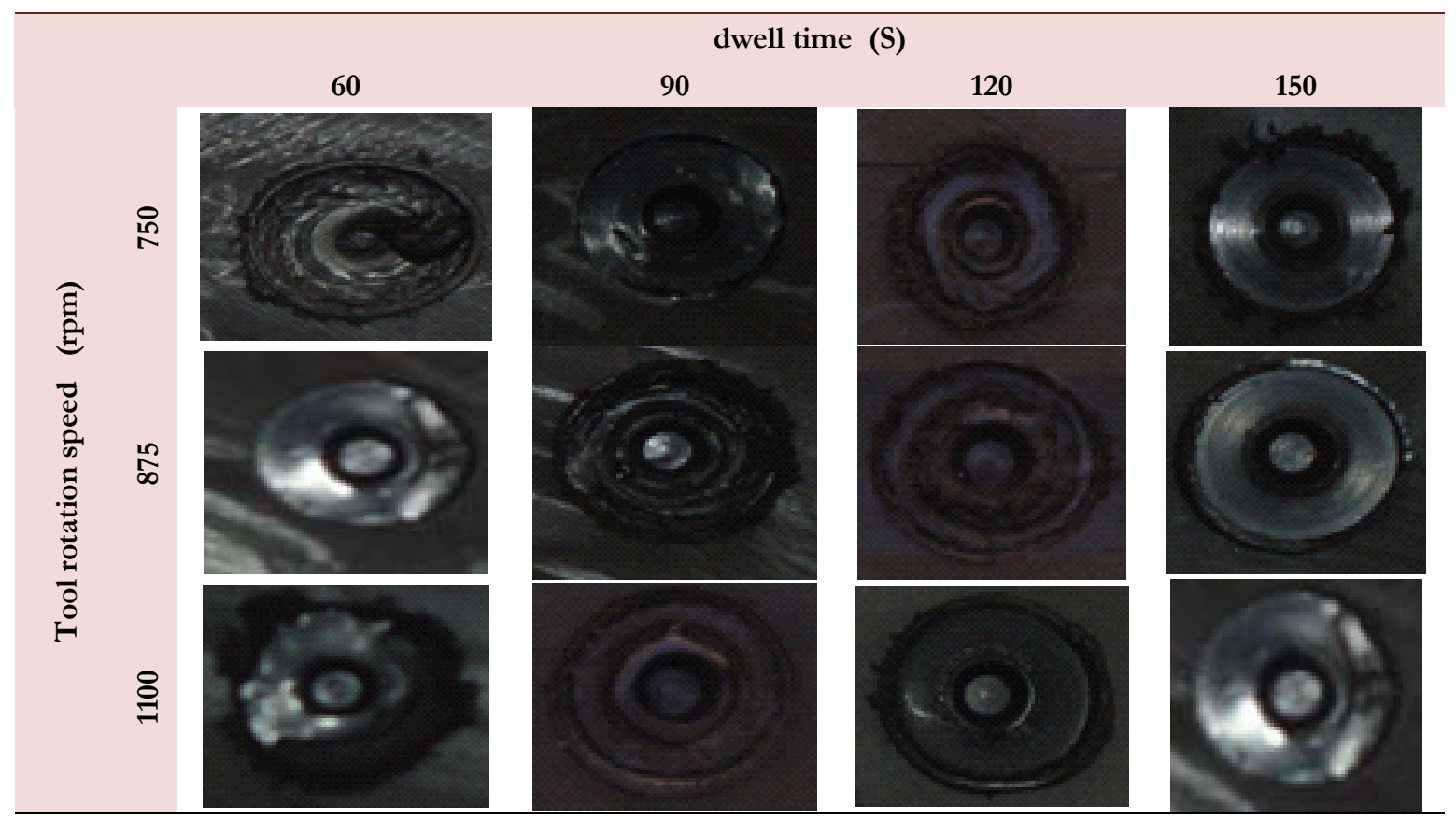

Table 3: Joint production form on upper sheet after friction stir spot welding at different parameters

\section{Tensile test}

Tensile-shear tests were performed on universal testing machine Instron/5887 at room temperature. The movement of the mobile traverse of the machine allows us to directly measure the automatic displacement of the specimen during the test using integrated software. The quasi-static tensile test was carried out under a crosshead speed of $5 \mathrm{~mm} / \mathrm{s}$. The load and the displacement are registered simultaneously during the tests. The typical load-displacement curves of HDPE sheets (without welding) and lap shear joint of HDPE (FSSW test) obtained by monotonic loading are shown in Fig. 6. It can be seen from this figure that the influence of welding process on the monotonic load displacement curves of HDPE is very significant, where the tensile strength increases with the increase of the tool rotating speed. From the tensile test results, the following inferences can be derived

- Tool rotational speed has a significant effect on tensile strength of the joints.

- Tensile failure loads of the joints increase with the increase in tool rotational speed.

This phenomenon can be explained by the fact of temperature level change and produces higher heat input in stir zone, which lead to change in stir zone strain and consequently, the initiation and crack growth is located within the contact zone (stir zone). The same conclusion has been found by other authors [40, 41].

\section{Effect of tool rotating speed and dwell time}

Fig. 7 shows an overview of the tool rotational speed and dwell time effect on the weld joint behavior. we notice that tool rotation speed and dwell time and its interaction in contact zone have a significant effect on the peak of lap shear tensile load, the maximum value is obtained for rotation speed of $1100 \mathrm{rpm}$ and dwell time $\mathrm{t}=120 \mathrm{~s}$. These values were 
considered the optimum parameters of FSSW for this HDPE and must be used to obtain high quality welds and increase its strength. From the results, we deduce that the operating point of these parameters is established for $1100 \mathrm{rpm}$ tool rotational speed and $120 \mathrm{~s}$ dwell time giving a maximum shearing force equal to $2155 \mathrm{~N}$. These parameters represent the optimal welding values. The maximum load is for $1100 \mathrm{rpm}$ and begins to decrease until it reaches a minimum value for $750 \mathrm{rpm}$. In order to investigate the tool rotating speed effect on failures mechanical behavior of HDPE lap-shear joint welded by FSSW process, three values of tool rotating speed V $(750,875,1100 \mathrm{rpm})$ were considered at room temperature. Fig. 8 shows the typical load-displacement curves of the HDPE lap shear joint (FSSW test) for a dwell time of 120s. The average failure loads for these rotational speed values of the tool welds in lap-shear specimens are changed from $1.5 \mathrm{KN}$ for $\mathrm{V}=750 \mathrm{rpm}$ to $2.15 \mathrm{KN}$ for $\mathrm{V}=1100 \mathrm{rpm}$. Tensile tests have shown that the sample with $1100 \mathrm{rpm}$ and 120s has good welding quality. The locations of the load drops in the load-displacement curves of HDPE lap-shear joint is possible correspond to different stages of the crack initiation at the interface and propagation occurred in these joints specimens during the tests. Further investigation should be conducted to fully investigate this phenomenon. The tensile/shear strength of the joint increased with increasing tool rotational speed according to Fig. 9.

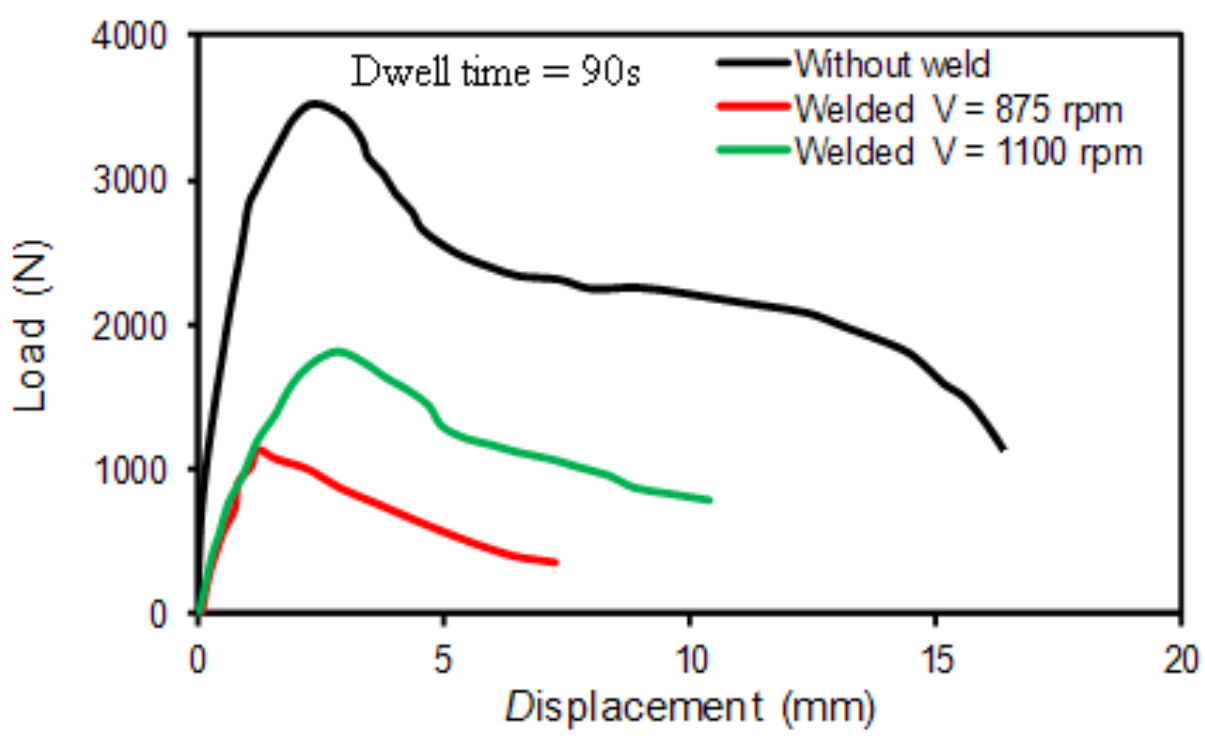

Figure 6: Load versus displacement curves of specimens for dwell time $=90 \mathrm{~s}$

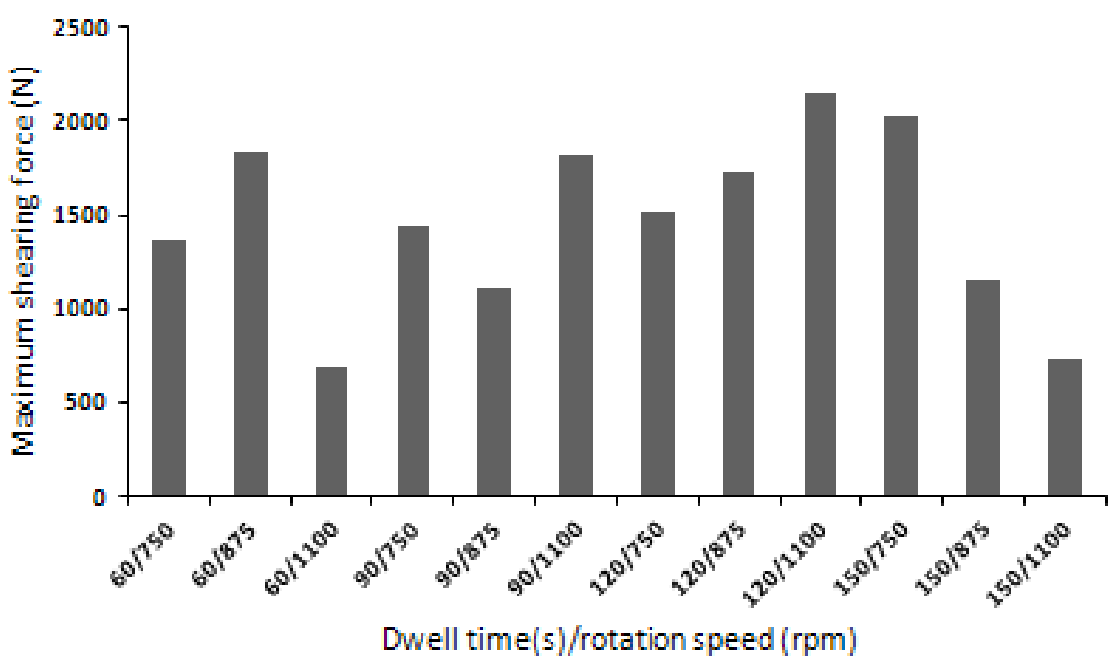

Figure 7: comparison diagram of the tensile / shear strength for the different FSSW welding parameters

We have analyzed the effect of dwell time on the mechanical performance of HDPE lap-shear tensile load. The optimum parameters used in this study to obtain high quality welds are $1100 \mathrm{rpm}$ tool rotational speed and $120 \mathrm{~s}$ dwell time as 
shown in Fig. 7. Fig. 10 illustrates the effect of dwell time on lap-shear tensile load of the friction stir spot welding joints for $1100 \mathrm{rpm}$ tool rotation speed.

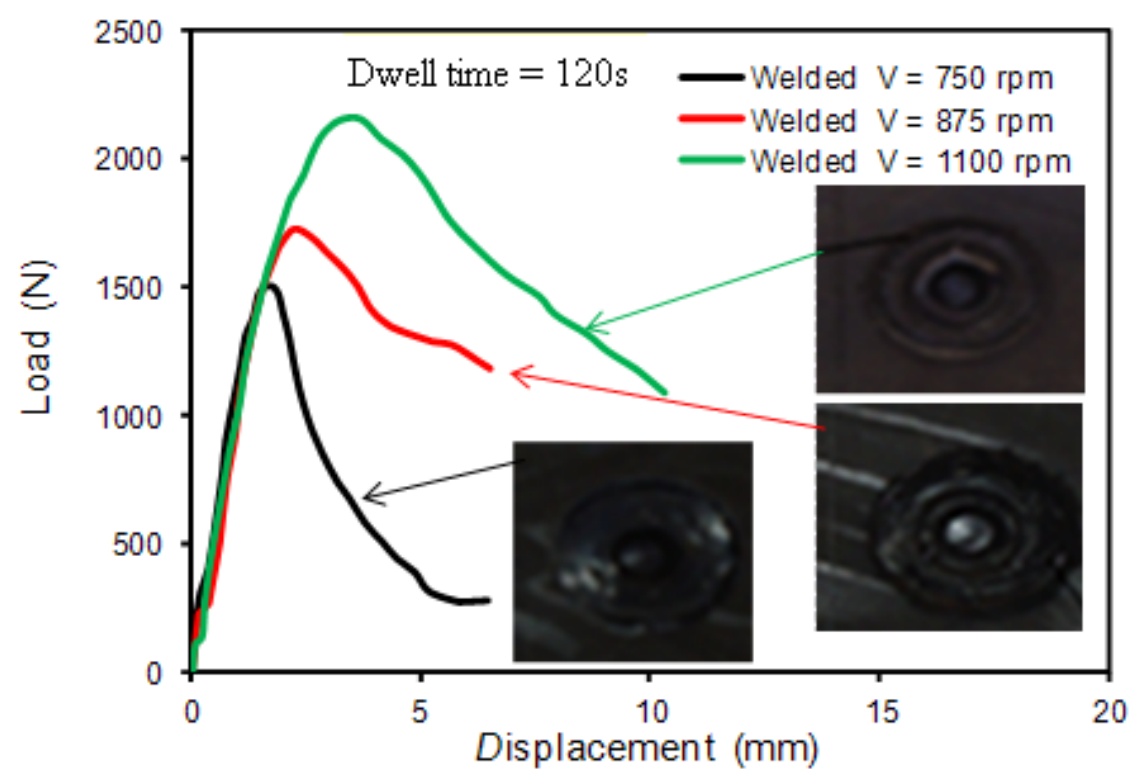

Figure 8: Load-displacement curve, effect of rotational speed for dwell time $=120 \mathrm{~s}$

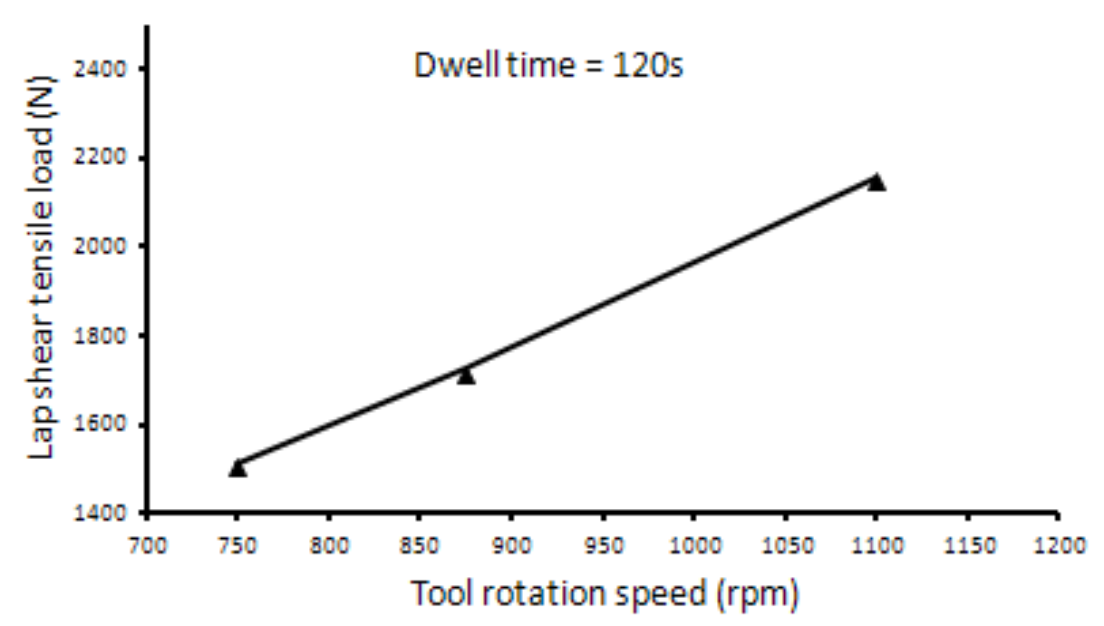

Figure 9: Tool rotation speed effect

We can notice that there is an increase in weld tensile shear strength from 60 s to 120 s of dwell time, and the maximum tensile load was obtained with the $120 \mathrm{~s}$ dwell time as shown in Fig. 10. Beyond $120 \mathrm{~s}$, the weld strength decreased with increasing dwell time Fig. 10. During the welding process, there is an increase in frictional heat production as the dwell time increased and the change of shear strength values explained by the fact that there are the formation of four microstructures zones in welded joint, namely the: stir zone (SZ), thermo mechanical affected zone (TMAZ), Heat affected zone (HAZ) and unaffected base material zone (BMZ). The growth of grains in these zones and especially in SZ and TMAZ was influenced by the combination of mechanical deformation and heat input which also depends on the parameters of welded process (tool rotational speed and dwell time). On the other hand, an increasing of the dwell time lead to a more mechanical strain of the SZ and TMAZ and consequently influenced on the mechanical behavior of HDPE materials.

Finally, we observe that the FSSW welded strength depends on the tool rotation speed and the dwell time. 


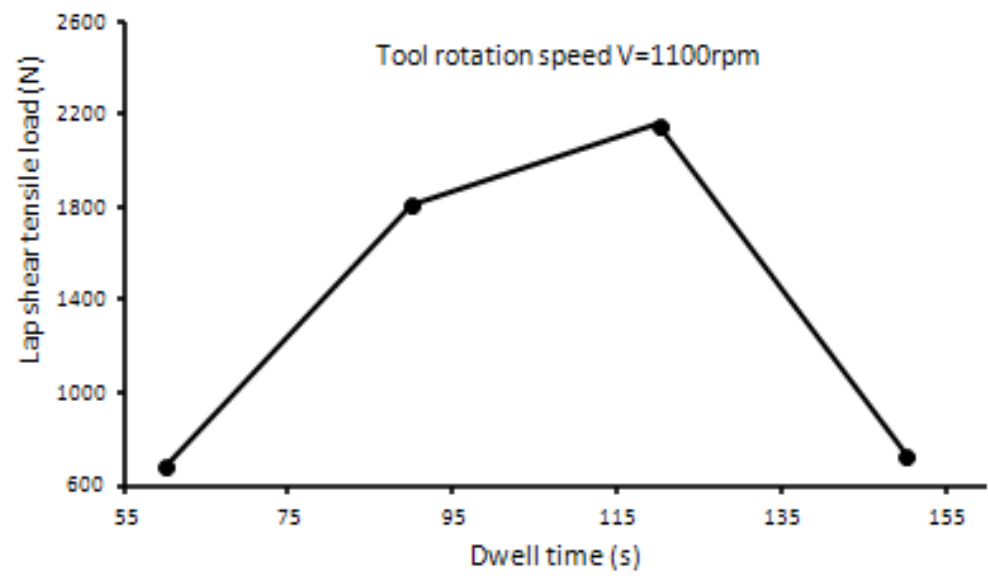

Figure 10: Dwell time effect

\section{NUMERICAL ANALYSIS AND RESULTS}

7 he processes of friction-stir spot welding (FSSW) have been widely and extensively used to join sheet metals in the automotive components. However, the stress field close to the contact region (stir zone: SZ and thermo mechanical affected zone: TMAZ) is very complex and far from being achieved. Meanwhile, these structures are also subjected to multi-axial loads during service. Although the relative displacement, stress and stain cannot be easily measured and its values are required, the analysis of stresses field at process zone (stir zone: SZ and thermo mechanical affected zone: TMAZ) under given loading condition is important to predict the fracture and the reliability of welded structure. Moreover, the welded polymer modeling is not fully understood and represents a very active research field. This work focuses on numerical simulation using finite elements to predict the overall behavior of welded assembly. Finite element analysis (FEA) is an important tool to design practical mechanical joints, such as HDPE lap shear joints by FSSW process.

During FSSW process, the tool undergoes a low strain so it is modeled as rigid material. Its mechanicals properties are young modulus $\mathrm{E}=200 \mathrm{MPa}$ and Poisson's ratio 0.3. An elastic-plastic response was considered for modeling the HDPE lap-shear joint welded by FSSW. The mesh is designed to be highly refined in the interface and near the process zone (SZ and TMAZ zones) in order to obtain more accurate results (typical element dimension in these zones is $0.2 \mathrm{~mm}$ ). In addition, a master-slave approach is used to simulate numerically the contact problems in the interfaces between all connected parts of lap-shear joint. The Coulomb friction law in a partial sliding/sticking condition was employed, where the friction coefficient was set at 0.25 .

According to the structure dimensions, a three dimensional model was generated using the FEM in order to determine and to perform the stress and strain field analyses in process zone (SZ and TMAZ zones).

A general description of the geometric model and the mesh of the studied assembly are presented in Fig. 11 and Fig. 12. The different boundary conditions and loading are detailed by highlighting the consideration of all the contact surfaces related to the specificity of such an assembly. Fig. 11 illustrate a lap-shear joint and the boundary conditions employed in the finite element models. A three-dimensional brick element (hexahedral) is used for the modeling, this element is defined by eight nodes and each having three degrees of freedom. The optimized model has 7782 nodes and 3315 elements for lap-shear joint welded by FSSW. The theory of incremental plasticity is introduced to modeling the material nonlinearity. The iterative method of Newton-Raphson is used as an approach to solve nonlinear equations by finite elements.

The variation of the various cylinders geometry is based on the variation of its thickness, its diameter and its shape. The reference thickness is $1.5 \mathrm{~mm}$. The model has 8900 nodes and 6592 elements for this configuration of tool. Whatever the geometry of the joint, the geometric modifications made: rigid surface at the contact of the two plates the lower plate and the upper plate, rigid surface formed of two cylinders introduced into the two plates, solid cylinder and a cylinder of hollow conical shape.

Fig. 13 show that the high equivalent stress is strongly concentrated at the interface between the plates. This phenomenon can be explained by the fact of strain incompatibility at the interface and the sliding effect. The optimal form will be tested later on a bilateral model to see how the result extends to multiple joints. 

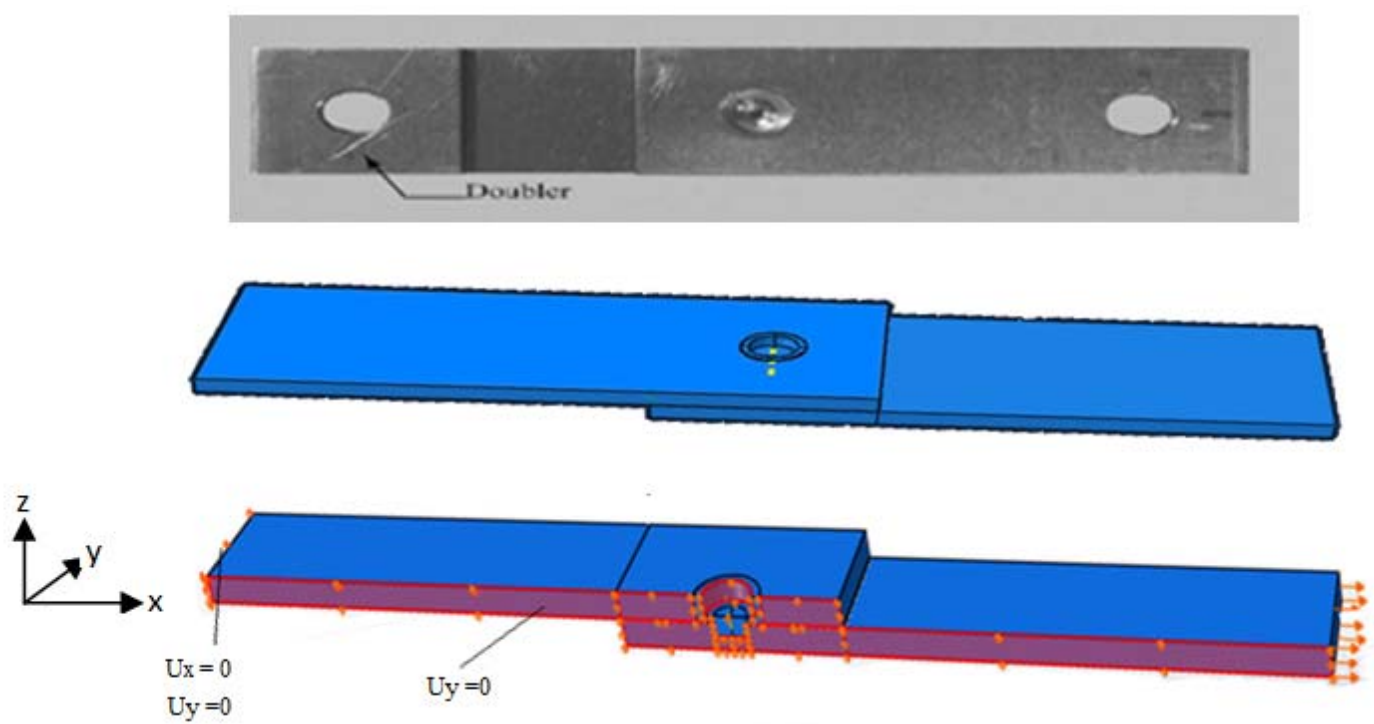

Figure 11: Geometrical model: half of a lap-shear joint, boundary condition and loading.
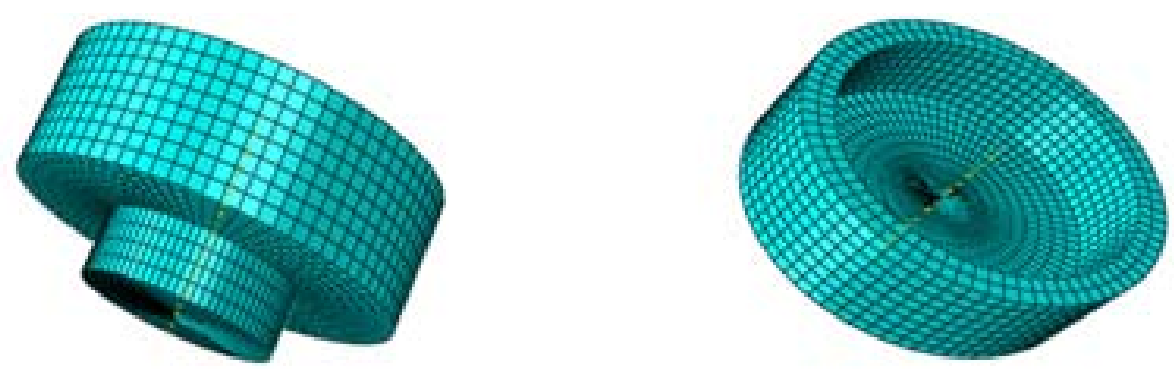

Figure 12: joint geometry and Mesh (contact zone)
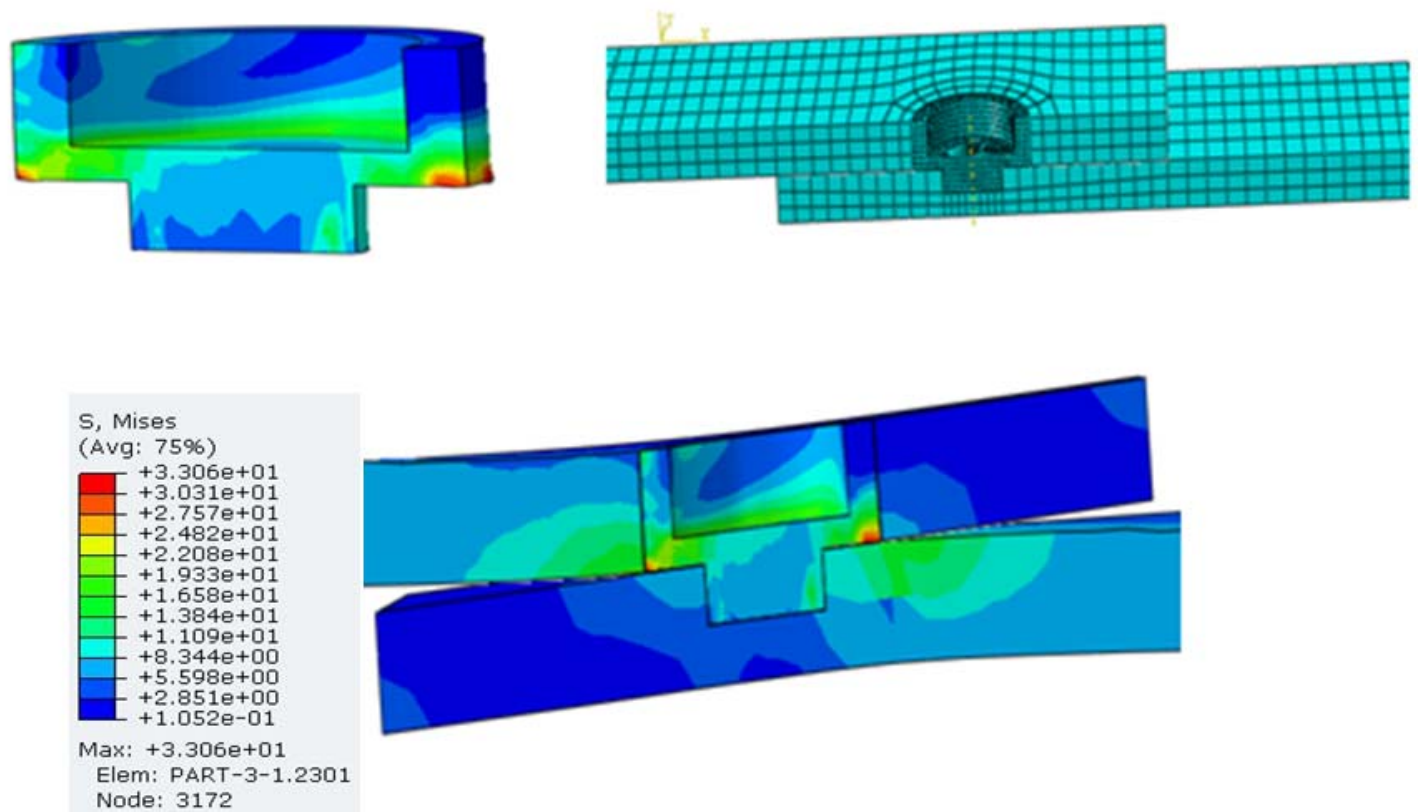

Figure 13: Numerical result for a weld spot 


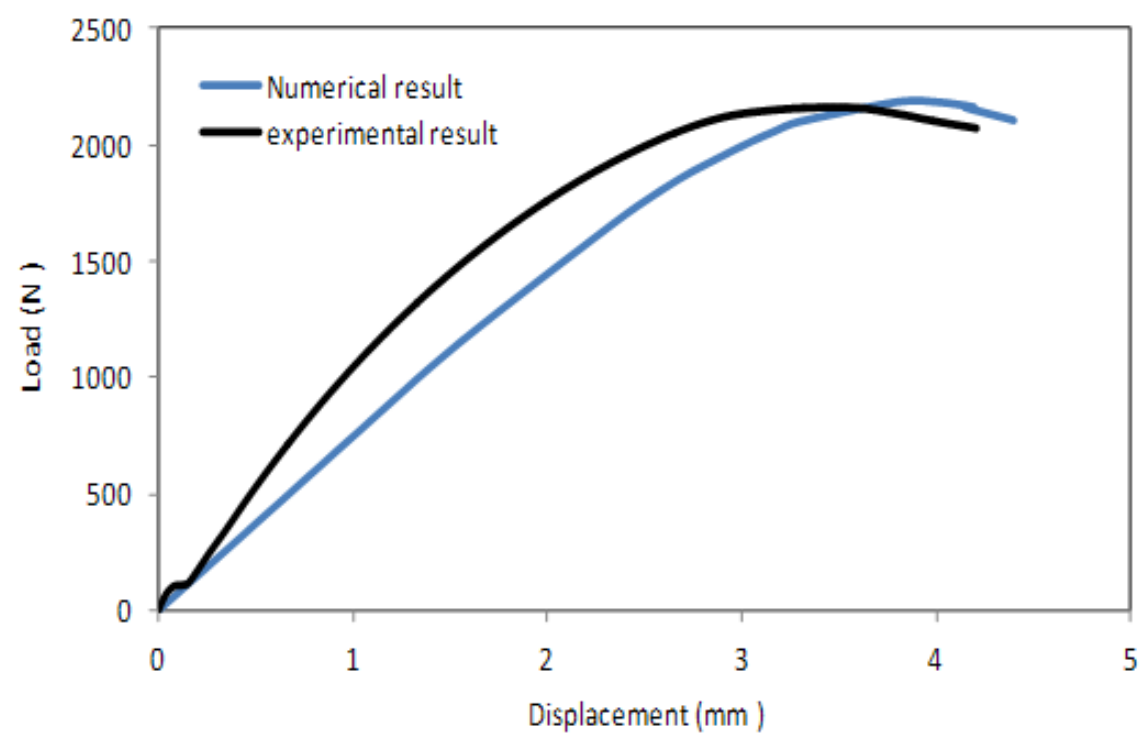

Figure 14: mechanical behavior of lap shear joints by FSSW

Fig. 14 illustrate the responses obtained from the mechanical behavior of the materials in terms of lap-shear tensile load versus displacement response during the tensile test and predicted by the numerical model taken for the optimum values, a speed of rotation of $1100 \mathrm{rpm}$ and a dwell time of $120 \mathrm{~s}$ which gave a good welding quality. From this figure, the results obtained numerically compared with the experimental results are presented. From a qualitative point of view the evolutions present similar behavior. The explanation of this mechanical behavior is that the deformation response of an amorphous polymer (HDPE) strongly depends on the stress conditions but also on the environment and the effect of the welding parameters (dwell time and tool rotating speed). Temperature is a very important parameter conditioning the response of polymers. It can be seen that the numerical results are in good agreement with the experimental results. This phenomenon can be explained by the fact, that the friction stir spot welding parameters has a significant effect on the material mixing and consequently on the static strength of welded joints. We recall also, that is difficult to make a complete characterization of welded joints behavior by FSSW process. In other words, creation of complex phenomena in welded zone during the welding process which related to the level and the interaction between the welded parameters such as: tool geometry, tool rotational speed and dwell time from where a difficulty to make a precise and reliable numerical analysis.

\section{CONCLUSIONS}

$\mathrm{F}$ riction stir spot welding of polymer materials is a promising technique which provides high quality joints compared to conventional welding processes. This study was carried out in order to analysis the effect of some parameters on the mechanical behavior of HDPE single lap joint welded by friction-stir spot welding (FSSW) under tensile loading. The obtained results allow us to deduce the following conclusions:

- The developed a nonlinear finite element modeling approach to simulate the single-lap joints welded by (FSSW) and subjected to static tensile loading.

- Good correlation was found between the FEM simulations and the experimental results.

- The level of tool rotating speed determines the mode failure of welded assemblies and on the mechanical behavior of HDPE material compared to HDPE sheets without welding.

- We can obtained a high quality welds and high quality weld strength using the optimum welding parameters (tool rotation speed and dwell time).

- The results found confirm that the tool rotation speed and dwell time play a predominant role in determining the tensile / shear strength.

- The increase in Dwell time increases the tensile shear strength in a limited range of FSSW joints.

- Tensile failure loads of the joints increase with the increase in tool rotational speed 


\section{ACKNOWLEDGMENTS}

he authors warmly thank the scientific support of the three research teams, LSTE laboratory and LPQ3M
laboratory from Mustapha Stambouli University, Mascara, Algeria and Lille Mechanics Unit (France).

\section{REFERENCES}

[1] Benhamena, A., Bachir Bouiadjra, B., Amrouche, A., Mesmacque, G., Benseddiq, N., Benguediab, M., (2010). Three finite element analysis of semi-elliptical crack in high density poly-ethylene pipe subjected to internal pressure. Materials and Design. 31 (6), pp. 3038-3043. DOI: 10.1016/j.matdes.2010.01.029

[2] Benhamena, A., Aminallah, L., Bachir Bouiadjra, B., Benguediab, M., Amrouche, A., Benseddiq, N., (2011). J integral solution for semi-elliptical surface crack in high density poly-ethylene pipe under bending. Materials and Design. 32 (5), pp. 2561-2569. DOI: 10.1016/j.matdes.2011.01.045

[3] Moulai Ali, B., Ould Chikh, B., Meddah, H.M., Bachir Bouiadjra, B. (2019), Plasticity Effect on the Mechanical Behavior of an Amorphous Polymer, International Journal of Engineering Research in Africa, 43, pp 1-19.

DOI: 10.4028/www.scientific.net/JERA.43.1

[4] Khellafi, H., Meddah, H.M., Ould Chikh, B., Bouchouicha, B., Benguediab, M., Bendouba, M. (2015). Experimental and Numerical Analysis of the Polyvinyl Chloride (PVC) Mechanical Behavior Response, CMC, 49-50(1), pp.31-45.

[5] Abdel Nour Zaim, Benattou Bouchouicha, Hadj Miloud Meddah, El Bahri Ould Chikh, (2018). The Stress Triaxiality Effect under Large Plastic Deformation of a Polybutylene Terephthalate (PBT), International Journal of Engineering Research in Africa, 34, 13-28.

[6] Abdel Nour, Z., Chikh El Bahri, O., Benattou, B. (2018). Thermo-Mechanical Characterization of a Thermoplastic Copolyetherester (TPC): Experimental Investigation. Fibers and Polymers, 19(4), pp. 734-741.

[7] Pathak, S., Pradhan, S.K. (2020). Experimentation and optimization of HDPE pipe electro fusion and butt fusion welding processes. Materials Today: Proceedings. 27(3), pp. 2925-2929. DOI: 10.1016/j.matpr.2020.03.517.

[8] Bouchouicha, B., Zemri, M., Zaim, A., Ould Chikh, B. (2015). Estimation of the energy of crack propagation in different zones of a welded joint by the local technique, Int. J. Fract., 192, pp.107-116.

DOI 10.1007/s10704-015-9989-1

[9] Singh, V. P., Patel, S. K., Ranjan, A., Kuriachen, B. (2020). Recent research progress in solid state friction-stir welding of aluminium-magnesium alloys: a critical review. Journal of Materials Research and Technology, 9(3), pp. 6217-6256. DOI: $10.1016 /$ j.jmrt.2020.01.008

[10] Thomas, W.M., Nicholas, E.D. (1997). Friction stir welding for the transportation industries. Materials and Design, 18(4/6), pp. 269-273. DOI: 10.1016/S0261-3069(97)00062-9.

[11] Mishra, R.S., Ma, Z.Y. (2005). Friction stir welding and processing. Materials Science and Engineering: R: Reports, 50 (1-2/31), pp. 1-78. DOI: 10.1016/j.mser.2005.07.001.

[12] Lee, W. B., Yeon, Y. M., Jung, S. B. (2003). Joint properties of friction stir welded AZ31B- H24 magnesium alloy. Journal of Materials Science and Technology, pp. 785-790. DOI: $10.1179 / 026708303225001867$.

[13] Hancock, R. (2004), Friction welding of aluminum cuts energy costs by 99\%. Welding journal, 83 (2), pp. 40-43. https://wenku.baidu.com/view/dd05837d4028915f804dc2fb.

[14] Sundaram, N. S., Murugan, N. (2010), Tensile behavior of dissimilar friction stir welded joints of aluminium alloys. Materials and Design, 31(9), pp.4184-4193. DOI: 10.1016/j.matdes.2010.04.035.

[15] Barlas, Z, Uzun, H. (2010), Microstructure and mechanical properties of friction stir butt-welded dissimilar pure copper/brass alloy plates. Int. J. Mat., 101(6), pp. 801-807. DOI: 10.3139/146.110340.

[16] Amirizad, M., Kokabi, A.H., Abbasi Gharacheh, M., Sarrafi, R., Shalchi, B., Azizieh, M. (2006), Evaluation of microstructure and mechanical properties in friction stir welded A356+15\% $\mathrm{SiC}$ cast composite. Mater. Lett., 60, pp. 565-568. DOI: 10.1016/j.matlet.2005.09.035,

[17] Bozkurt, Y., Duman, S. (2011), The effect of welding parameters on the mechanical and microstructural properties of friction stir welded dissimilar AA 3003-H24 and 2124/SiC/25p-T4 alloy joints. Int. J. Phys. Sci., 6(17), pp. 3702-3716. DOI: $10.5897 /$ SRE11.616,

[18] Vijay, S.J., Murugan, N. (2010). Influence of tool pin profile on the metallurgical and mechanical properties of friction stir welded Al-10 wt.\% TiB2 metal matrix composite. Materials and Design, 31, pp. 3585-3589. 
DOI: 10.1016/j.matdes.2010.01.018.

[19] Rajamanickam, N., Balusamy, V., Madhusudhann, Reddy, G., Natarajan, K. (2009). Effect of process parameters on thermal history and mechanical properties of friction stir welds. Materials and Design 30 (7), pp. 2726-2731. DOI: 10.1016/j.matdes.2008.09.035.

[20] Grewell, D.A., Benatar, A., Park, J.B. (2003). Plastics and Composites Welding Handbook. Carl Hanser Verlag, Munchen.

[21] Strand, S. (2003). Joining plastics - Can friction stir welding compete. IEEE, 0-941783-23.

[22] Strand, S., Sorensen, C., Nelson, T. (2003). Effects of friction stir welding on polymer microstructure. ANTEC 2003 proceedings, 2, pp.1078-1082.

[23] Arici, A., Selale, S. (2007), Effects of Tool Tilt Angle on Tensile Strenght and Fracture Locations of Friction Stir Welding of Polyethylene, Science and Technology of Welding and Joining, 12, pp. 536-539. DOI: $10.1179 / 174329307 X 173706$.

[24] Kiss, Z., Czigany, T. (2007). Applicability of friction stir welding in polymeric materials. PeriodicaPolytechnica. 51(1): pp. 15-18. DOI: $10.3311 /$ pp.me.2007-1.02.

[25] Aydin, M. (2010), Effects of welding parameters and pre-heating on the friction stir welding of UHMW-PE. PolymerPlastics Technol. Eng., 49(6), pp. 595-601. DOI: 10.1080/03602551003664503.

[26] Bozkurt, Y. (2011). The optimization of friction stir welding process parameters to achieve maximum tensile strength in polyethylene sheets, Materials and Design. DOI:10.1016/j.mat des.2011.09.008.

[27] Payganeh, G.H., Mostafa Arab, N.B., Dadgar Asl, Y., Ghasemi, F.A., Saeidi, B. M (2011). Effects of friction stir welding process parameters on appearance and strength of polypropylene composite welds. Int. J. Phys. Sci., 6(19), pp. 4595-4601. DOI: 10.5897/IJPS11.866.

[28] Mendes, N., Neto, P., Simão, M.A., Loureiro, A., Pires, J.N. (2016), A novel friction stir welding robotic platform, welding polymeric materials. The International Journal of Advanced Manufacturing Technology, 85, pp. 37-46. DOI: $10.1007 / \mathrm{s} 00170-014-6024-z$.

[29] Aota, K., Ikeuchi, K. (2009), Development of friction stir spot welding using rotating tool without probe and its application to low carbon steel plates, Welding International 23, pp. 572-580. DOI: 10.1080/09507110802543054.

[30] Gerlich, A., Su, P., North, T., Bendzsak, G. (2005), Friction stir spot welding of aluminum and magnesium alloys, Materials Forum, 29, pp. 290-294. DOI: 10.4271/2005-01-1255.

[31] Arici, A., Senol, M. (2008), Friction Stir Spot Welding of Polypropylene, Journal of Reinforced Plastics and Composites, 27, pp. 2001-2004. DOI: 10.1177/0731684408089134.

[32] Bilici, M.K. and Yukler, A.I. (2012), Effects of welding parameters on friction stir spot welding of high density polyethylene sheets, Materials and Design, 33, pp. 545-550. DOI: 10.1016/j.matdes.2011.04.062.

[33] Bilici, M.K. and Yukler, A.I. (2012), Influence of tool geometry and process parameters on macrostructure and static strength in friction stir spot welded polyethylene sheets, Materials and Design, 33, pp. 145-152. DOI: 10.1016/j.matdes.2011.06.059.

[34] Bilici, M.K. Ahmet I. Y., Memduh K. (2016). Pin Profile and Shoulder Geometry Effects in Friction Stir Spot Welded Polymer Sheets, The International Journal Of Engineering And Science, 5(6), pp. 29-36. http://www.theijes.com/.

[35] Kurtulmus, M. (2012), Friction stir spot welding parameters for polypropylene sheets, Scientific Research and Essays, 7(8), pp. 947-956. DOI: 10.5897/SRE11.1909.

[36] Awang, M., Mucino, V., Feng, Z., David, S. (2006), Thermo-Mechanical Modeling of Friction Stir Spot Welding (FSSW). SAE Technical Paper 2006-01-1392, DOI: 10.4271/2006-01-1392.

[37] Hachellaf, K., Meddah, H. M., Ould Chikh, B., Lounis, A. (2019, Mechanical behavior analysis of the welding cord by Friction Stir Welding (FSW) for a polymer material, Frattura ed Integrità Strutturale, 47, pp. 459-467. DOI: $10.3221 /$ IGF-ESIS.47.36.

[38] Lounis, A., Ould Chikh, B., Meddah, H. M., Gueraiche, L., Hachellaf, K. (2018), Parametric Study of the Mechanical Behavior of FSSW Welded Polymer Plates Using a New Form of Welding Tool, Defect and Diffusion Forum, 389, pp 205-215. DOI: 10.4028/www.scientific.net/DDF.389.205.

[39] Catalogues groupe chiali (sidi bel-abbes -ALGERIA) - http:/www.groupe-chiali.com, (2017).

[40] Zhang, Z., Yang, X., Zhang, J., Zhou, G., Xu, X., Zou, B. (2011). Effect of welding parameters on microstructure and mechanical properties of friction stir spot welded 5052 aluminum alloy, Materials and Design 32. pp. 4461-4470. DOI: 10.1016/j.matdes.2011.03.058.

[41] Khuder, A. W. H., Muhammed, M. A., Ibrahim, H. K. (2017). Numerical and Experimental Study of Temperature Distribution in Friction Stir Spot Welding of AA2024-T3 Aluminum Alloy, International Journal of Innovative Research in Science, Engineering and Technology, 6 (5), DOI: 10.15680/IJIRSET.2017.0605004. 